\title{
Investigation of the prevalence of aggression against women by husbands in among the persons who are dependent to opium substance who were referred to an addiction clinic of the Medical University of Rafsanjan during the year 2004 Parvin Aghamohammadhasani*
}

Address: Moradi Hospital, Rafsanjan University, Iran

* Corresponding author

from International Society on Brain and Behaviour: 2nd International Congress on Brain and Behaviour Thessaloniki, Greece. 17-20 November 2005

Published: 28 February 2006

Annals of General Psychiatry 2006, 5(SuppI I):SI67 doi:I0.II86/I744-859X-5-SI-SI67

\section{Background}

Aggression against women is one of the social problem in all countries of the world. These social problems not only cause the mental and physical problems for the injured person but also canse so many social inevitable results.

\section{Materials and methods}

In this study, the dependents of opium gave there information to moradi hospital in Rafsanjan after ensuring that there informative would not be reviald by filling the questionnaire without mentioning their names. This study has been with 950 samples investigate of wife abuse frequency and the factors which effect on it.

\section{Results}

The rate of wife abuse among the addictional society was $75 \%$. By an over all investigations of these study factors such as to be young. Low graduation, not having a house, to be a worker, low income, extra use of doium, injection and use of heroin, all considered as the most important factors of wife abuse.

\section{Discussion}

So the common and special teachings in this field in order to prevent this social problem and also reporting of this cases by doctors and psychictrists to prevent the complications by it are recommended. 